\title{
Neoadjuvant Chemotherapy Effect on Predictive Value of Sentinel Lymph Node Biopsy using Single Method Methylene Blue in Breast Cancer Patients at Low-resource Country
}

\author{
Muhammad David Perdana Putra ${ }^{1 *}$, Kristanto Yuli Yarso ${ }^{2}$, Brian Wasita ${ }^{3}$ \\ ${ }^{1}$ Department of Surgery, Faculty of Medicine, Sebelas Maret University, Surakarta, Indonesia; ${ }^{2}$ Department of Surgery, Oncology \\ Division, Faculty of Medicine, Sebelas Maret University, Surakarta, Indonesia; ${ }^{3}$ Department of Pathology Anatomy, Faculty of \\ Medicine, Sebelas Maret University, Surakarta, Indonesia
}

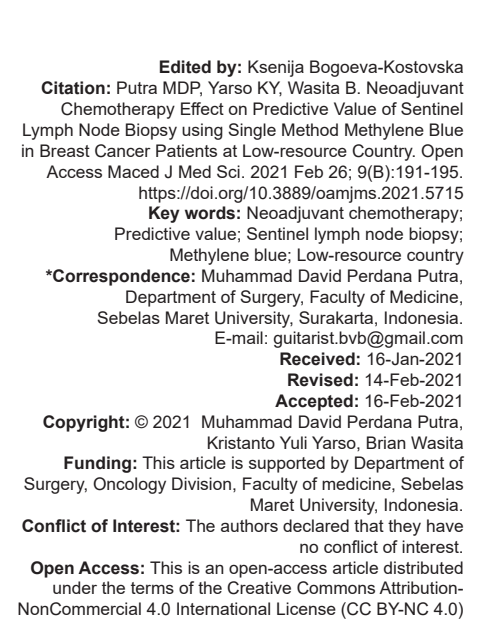

\section{Abstract}

AIM: This study aimed to examine the application of neoadjuvant chemotherapy (NAC) effect on sentinel lymph node biopsy (SLNB) using single method methylene blue $1 \%$ in breast cancer patients at low-resource country.

METHODS: This analytical observational study employed a retrospective case-control approach. The total sampling method was used by involving the entire population of Stage-I and -II breast cancer patients after performed core biopsy or open biopsy with clinically negative axillary lymph nodes that had performed SLNB and axillary lymph nodes dissection at several hospitals in Surakarta from January to May 2020. The descriptive data were presented in the frequency table. Sensitivity, specificity, positive predictive value, negative predictive value (NPV), and diagnostic values were reported with $95 \%$ confidence of interval $(\mathrm{Cl})$

RESULTS: From a total of 161 patients, 100 patients were given NAC. The identification rate of the non-NAC was $91.3 \%$ and the NAC group $80.6 \%$. Non-NAC group obtained a false-negative rate of $24.4 \%$ with NPV of $94.4 \%(95 \%$ $\mathrm{Cl} 85-100)$, while the false-negative rate of the NAC group was $10.8 \%$ with NPV of $74 \%(95 \% \mathrm{Cl} 65-80)$.

CONCLUSIONS: NAC with single method methylene blue $1 \%$ injection in SLNB can reduce the identification and false-negative rates in breast cancer patients.

\section{Introduction}

Sentinel lymph nodes (SLN) are nodes that receive the first spread of breast cancer metastases [1]. Surgical techniques can be performed with axillary lymph node dissection (ALND) or SLN biopsy (SLNB) [1]. ALND remains a standard procedure but is less useful for $70-80 \%$ of early-stage breast cancer patients with negative axillary nodules so that a better treatment is needed, that is, SLNB [2]. In breast cancer patients with clinically negative nodes, SLNB has better diagnostic accuracy than ALND by reducing morbidity and becoming a standard procedure for axillary with an accuracy of $>90 \%$ [3]. Based on these results, SLNB becomes negatives because mostly, ALND procedures are not performed. However, a study conducted by Lee et al. [4] showed a false-negative rate, ranging from $4.6 \%$ to $16.7 \%$ after SLNB. Several studies explain that the high false-negative rate of SLNB allows experts to perform ALND further [5], [6].
Neoadjuvant chemotherapy (NAC) is not only used in patients with advanced breast cancer and breast cancer with positive axillary nodules but it can also be used in early-stage breast cancer patients with negative axillary nodules [7], [8]. According to Mamounas et al. [9], the accuracy of SLNB in post-NAC patients can be reduced with an average identification rate of $83 \%$ and an average false-negative rate of $11 \%$. NAC causes damage to lymphatic drainage due to shrinkage and fibrosis by inducing fat degeneration as a result of the tumor cell apoptotic process. This decreases SLNB accuracy in post-NAC patients [10].

In developed countries, the optimal technology for SLNB uses patent blue dye, preoperative lymphoscintigraphy, and radioisotope tracer, which are used as a single or combination technique [11]. Limited access to the optimal technology for SLNB is the main problem in Indonesia. The cost to provide nuclear medicines in every hospital has contributed to the difficulty for administering SLNB optimally. As an alternative to these devices, we sought to evaluate 
NAC effect on the identification rate and false-negative rate of SLNB using single method methylene blue $1 \%$ in breast cancer patients at low-resource country.

\section{Materials and Methods}

This analytical observational study employed a retrospective case-control approach. The total sampling method was used by involving the entire population of Stage-I and -II breast cancer patients after performed core biopsy or open biopsy with clinically negative axillary lymph nodes that met the study requirements at several hospitals in Surakarta from January to May 2020. This study has been approved by the Ethics Committee of the Sebelas Maret University Indonesia number 620/III/HREC/2020.

The data were obtained from the secondary data of patients with clinically node negative without perform an axillary biopsy if the axillary ultrasonography found a suspicious lymph node, we performed SLNB using single methylene blue $1 \%$ and ALND. The samples were then assigned into two groups, namely, the NAC group, who underwent NAC, and the control group or non-NAC group, who did not undergo NAC.

The samples from both groups were given a periareolar or peritumoral injection of single methylene blue 1\% $20 \mathrm{~min}$ before operation and then massaged for $5 \mathrm{~min}$. And then observed to find out the results intraoperatively, positive or negative, by observing whether the color changed to blue or not. The blue nodes and the palpable suspicious nodes were taken. Then, the samples underwent a histopathological examination.

The data were then analyzed statistically to determine the identification rate and false-negative rate. The identification rate was known by counting the number of patients with positive SLNB results histopathologically. The false-negative rate was known by counting the number of patients with negative SLNB results but positive tumor histopathologically after ALND. The descriptive data were presented in the frequency table. Sensitivity, specificity, positive predictive value, negative predictive value (NPV), and diagnostic values were reported with $95 \%$ confidence of interval $(\mathrm{Cl})$. Data analysis was performed using SPSS version 25.0 .

\section{Results}

\section{Patient characteristics}

Retrospectively, 161 patients were obtained from January to May 2020. Of the 148 patients included in the final analysis, they were assigned to the NAC group and non-NAC group (Figure 1). The average age was 47 years (27-81 years) in the NAC group and 50 years (2682 years) in the non-NAC group. Forty-seven patients in the non-NAC group (77\%) underwent a core biopsy, while 92 patients $(92 \%)$ in the NAC group underwent open biopsy. Periareolar injection of methylene blue $1 \%$ was administered to most patients, 57 patients (93\%) in the non-NAC group, and 90 patients $(90 \%)$ in the NAC group. The median size of the tumor was $3(1-6 \mathrm{~cm})$. Invasive ductal carcinoma was the most common outcome found in 49 non-NAC patients $(80 \%)$ and 70 NAC patients (70\%). Mastectomy was the most common surgical procedure performed to 32 non-NAC patients (52\%), while the breast conservative surgery (BCS) procedure was performed to 71 NAC patients (71\%) (Table 1).

Table 1: Patient characteristics $(n=161)$

\begin{tabular}{|c|c|c|c|c|c|}
\hline $\begin{array}{l}\text { Patient } \\
\text { characteristics }\end{array}$ & $\begin{array}{l}\text { Neoadjuvant } \\
\text { chemotherapy } \\
\text { Group (n: 100) }\end{array}$ & Percentage & $\begin{array}{l}\text { Non-neoadjuvant } \\
\text { chemotherapy } \\
\text { Group (n: 61) }\end{array}$ & Percentage & $p$-value \\
\hline \multicolumn{6}{|l|}{ Age (years) } \\
\hline$<40$ & 32 & 32 & 20 & 33 & \multirow[t]{2}{*}{0485} \\
\hline$>40$ & 68 & 68 & 41 & 67 & \\
\hline \multicolumn{6}{|l|}{ Biopsy } \\
\hline Core & 8 & 8 & 47 & 77 & \multirow[t]{2}{*}{0502} \\
\hline Open & 92 & 92 & 14 & 23 & \\
\hline \multicolumn{6}{|c|}{ Injection location } \\
\hline Periareolar & 90 & 90 & 57 & 93 & \multirow[t]{2}{*}{0285} \\
\hline Peritumoral & 10 & 10 & 4 & 7 & \\
\hline \multicolumn{6}{|c|}{ Histopathology results } \\
\hline IDC & 70 & 70 & 49 & 80 & \\
\hline ILC & 28 & 28 & 11 & 19 & \multirow{2}{*}{0125} \\
\hline Others & 2 & 2 & 1 & 1 & \\
\hline \multicolumn{6}{|l|}{ T status } \\
\hline T1 & 18 & 18 & 13 & 22 & \multirow{2}{*}{0973} \\
\hline T2 & 82 & 82 & 48 & 78 & \\
\hline \multicolumn{6}{|l|}{ Tumor grade } \\
\hline 1 & - & - & - & - & \multirow{3}{*}{0275} \\
\hline 2 & 61 & 61 & 46 & 90 & \\
\hline 3 & 39 & 39 & 15 & 10 & \\
\hline \multicolumn{6}{|l|}{ Operation } \\
\hline BCS & 71 & 71 & 29 & 48 & \multirow[t]{2}{*}{0203} \\
\hline Mastectomy & 29 & 29 & 32 & 52 & \\
\hline
\end{tabular}

\section{SLNB and histopathological examination}

In this study, SLN was obtained from 46 patients in the non-NAC group and 56 patients from the NAC group. Cases of SLN with positive metastases were found in 27 of 46 patients in the non-NAC group, which resulted in an identification rate of $91.3 \%$. Meanwhile, in the NAC group, SLN cases were found with positive metastases in 24 of 56 patients, which resulted in an identification rate of $80.6 \%$. The average number of SNs that could be identified was two (1-8) in both groups.

In the non-NAC group, 19 patients could be identified without metastases. Eleven patients had metastases in their axillary lymph nodes, which resulted in a false-negative rate of $24.4 \%$ with NPV of $94.4 \%$ (95\% Cl 85-100) (Tables 2 and 4). In the NAC group, SLN was obtained without metastases in 32 patients with nine patients experiencing metastases in axillary lymph nodes, which showed a false-negative rate of $10.8 \%$ with NPV of $74 \%(95 \% \mathrm{Cl} 65-80)$ Tables 2 and 4). In the non-NAC group, there were 27 patients with metastases in SLN and axillary lymph nodes. Meanwhile, in the NAC 
group, 24 patients with SLN metastases were found, 13 of who showed axillary metastases.

Table 2: Characteristics of patients with false-negative rate

\begin{tabular}{lllll}
\hline Patient Characteristics & $\begin{array}{l}\text { Neoadjuvant } \\
\text { chemotherapy } \\
\text { Group }\end{array}$ & $\begin{array}{l}\text { Percentage } \\
(\%)\end{array}$ & $\begin{array}{l}\text { Non-neoadjuvant } \\
\text { chemotherapy } \\
\text { group }\end{array}$ & Percentage \\
\hline $\begin{array}{lllll}\text { Age (years) } \\
<40\end{array}$ & 3 & 33 & 3 & 28 \\
$>40$ & 6 & 67 & 8 & 72 \\
T Status & - & - & 1 & 10 \\
T1 & 9 & 100 & 10 & 90 \\
T2 & & & & 72 \\
Histopathology results & & 67 & 8 & 19 \\
IDC & 6 & 33 & 2 & 9 \\
ILC & 3 & - & 1 & - \\
Others & - & - & - & 37 \\
Tumor grade & - & 12 & 4 & 63 \\
1 & 2 & 88 & 7 & \\
2 & 8 & & & \\
3 & & & & \\
\hline
\end{tabular}

\section{Unidentified SLN}

In the non-NAC group, there were 15 patients with unidentified SLN with an average age of 50 years (36-63 years). Four patients (27\%) had a Grade-II tumor, and 11 patients (73\%) had Grade-III tumor. Based on the histopathology, 12 patients (80\%) had invasive ductal carcinoma. Five patients showed axillary lymph node metastases, and others were negative.

In the NAC group, 44 patients presented with unidentified SLN were with an average age of 42 years (28-60 years). There were seventeen patients (39\%) with Grade-II tumors and 27 patients (61\%) with Grade-III patients. Invasive ductal carcinoma was the most histopathological found in 30 patients (68\%). Ten patients had metastases in their axillary lymph nodes (Table 3).

Table 3: Characteristics of patients with unidentified sentinel lymph node

\begin{tabular}{lllll}
\hline $\begin{array}{l}\text { Patient } \\
\text { Characteristics }\end{array}$ & $\begin{array}{l}\text { Neoadjuvant } \\
\text { chemotherapy } \\
\text { group }\end{array}$ & Percentage & $\begin{array}{l}\text { Non-neoadjuvant } \\
\text { chemotherapy Group }\end{array}$ & Percentage \\
\hline $\begin{array}{lllll}\text { Age (years) } \\
<40\end{array}$ & 11 & 25 & 5 & 34 \\
$>40$ & 33 & 75 & 10 & 66 \\
Histopathology & results & & & \\
IDC & 30 & 68 & 12 & 80 \\
ILC & 12 & 27 & 2 & 13 \\
MC & 2 & 5 & 1 & 7 \\
Tumor grade & - & - & & 27 \\
1 & 17 & 39 & 4 & 73 \\
2 & 27 & 61 & 11 & 34 \\
3 & 10 & 77 & 5 & 66 \\
Axillary lymph node metastasis & & 10 & \\
Positive & 10 & 23 & & \\
Negative & 34 & \multicolumn{2}{l}{ Remark: IDC: Invasive ductal carcinoma, ILC: Invasive lobular carcinoma, MC: Medullary carcinoma. }
\end{tabular}

\section{Statistical analysis}

The results of the analysis showed that the parameters of age $(p=0.485)$, tumor size $(p=0.973)$, tumor grade $(p=0.275)$, biopsy type $(l=0.502)$, and injection location $(p=0.285)$ were not related to SLN identification.

\section{Discussion}

Most breast cancer cases in Indonesia are of the advanced stage when compared to some developed countries [12], [13]. It is what makes ALND is generally performed by surgeons in Indonesia. This study had a retrospective case-control research design, which aimed to determine whether NAC could affect the SLN identification rate and false-negative rate using methylene blue $1 \%$ as a lymphatic mapping standard before SLNB. Although the standards for lymphatic mapping in developed countries have supported combination techniques, limited access to radioisotope tracking and nuclear medicine in Indonesia is currently a constraint. The study conducted by Brahma et al. [14] showed that the use of methylene blue $1 \%$ was effective in identifying SLN with a sensitivity of $92 \%$ so that it could still be applied in Indonesia if no sophisticated lymph node mapping facilities were found. Fifty-seven patients (93\%) in the non-NAC group and 90 patients $(90 \%)$ in the NAC group had a periareolar injection of single methylene blue $1 \%$. It is following the study of Borgstein et al. [15] and Shimazu et al. [16], which compared peritumoral injection with periareolar injection, which is an ideal technique in the identification of SLN in early-stage breast cancer patients.

In this study, the identification rate was $91.3 \%$ in the non-NAC group, but it decreased in the NAC group by $80.6 \%$. In the NAC group, SLNs were identified as having decreased, that is, 23 patients $(71 \%)$ had negative lymph nodes for axillary metastases with a false-negative rate of $10.8 \%$, lower than that of the non-NAC group, which was $24.4 \%$. According to the previous study, chemotherapy causes lymphatic drainage damage due to shrinkage and fibrosis by inducing fat degeneration due to the process of tumor cell apoptosis [11]. It causes SLNB accuracy in postNAC patients to decrease. With this in mind, it is recommended that future studies can reduce ALND to save patients who have received NAC from having the risk of lymphedema and other morbidities.

The AMAROS and IBCSG 23-01 studies explain a new perspective for eliminating ALND after positive SLN [17]. Based on these studies, with specific criteria for small-sized tumors, BCS, and breast radiation can be performed. This selection criterion does not fit most of the characteristics of the patients in the non-NAC group, as shown in this study, where there were 48 patients (78\%) with larger tumor size, T2, and 46 patients $(90 \%)$ with a Grade-II tumor. In the NAC group, 82 patients (82\%) had T2 tumors, and 61 patients $(61 \%)$ had a Grade-II tumor, and mastectomy was preferred by a non-NAC group than BCS. In this study, the histopathological results showed that 119 patients (73\%) had invasive ductal carcinoma. In another study conducted by Soebhi et al. [18], the same results were obtained, in which there were 687 breast cancer patients 


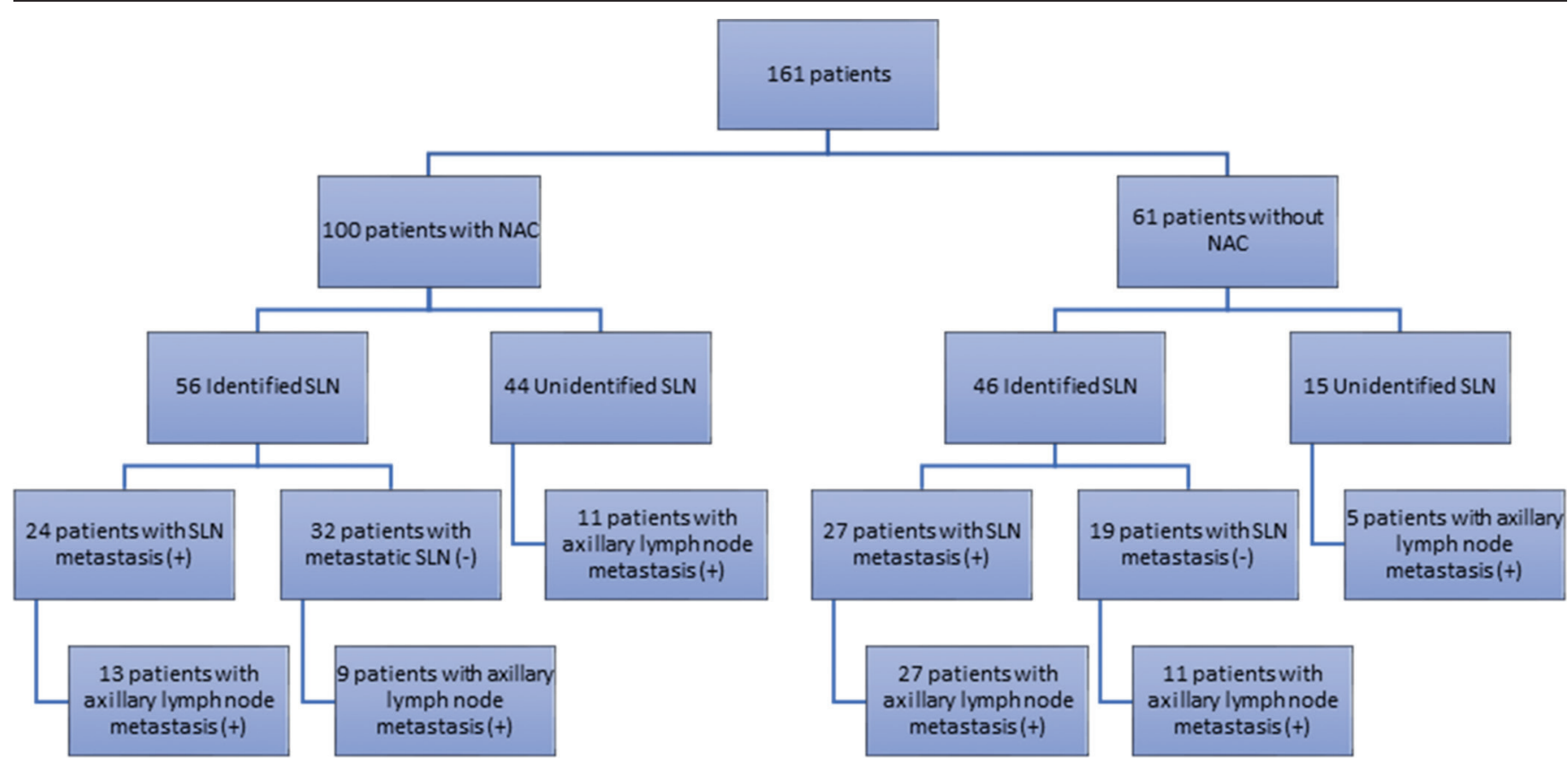

Figure 1: Chart of patient. Remark: NAC: Neoadjuvant chemotherapy, SLN: Sentinel lymph node

Table 4: Diagnostic score sentinel lymph node

\begin{tabular}{|c|c|c|c|c|c|}
\hline Groups & $\mathrm{Se}$ & Sp & Positive predictive value & Negative predictive value & FNR \\
\hline Neoadjuvant chemotherapy group & 80.6 & 74.0 & 79.8 & 74.0 & 10.8 \\
\hline & $95 \% \mathrm{Cl}(71-89)$ & $95 \% \mathrm{Cl}(65-80)$ & $95 \% \mathrm{Cl}(71-89)$ & $95 \% \mathrm{Cl}(65-80)$ & \\
\hline Non-neoadjuvant chemotherapy group & $\begin{array}{l}91.3 \\
95 \% \mathrm{Cl}(81-99)\end{array}$ & $\begin{array}{l}94.4 \\
95 \% \mathrm{Cl}(85-100)\end{array}$ & $\begin{array}{l}91.3 \\
95 \% \mathrm{Cl}(81-99)\end{array}$ & $\begin{array}{l}94.4 \\
95 \% \mathrm{Cl}(85-100)\end{array}$ & 24.4 \\
\hline
\end{tabular}

with an average age of 48.5 years in Indonesia, $89 \%$ of whom had invasive ductal carcinoma outcomes.

Brahma et al. [14], in their study, found an NPV value of $91.1 \%$. The NPV in the non-NAC group of the current study was realized higher than that in another study of $94.4 \%$, which might have been caused by 11 false-negative cases that had a higher median tumor size $(4 \mathrm{~cm})$ in about ten patients $(90 \%)$, and higher tumor grade (63\% with the Grade- 3 tumor). Thus, patients with tumor size $>3 \mathrm{~cm}$ and high-grade tumors may have a higher risk of developing metastases and blockage of the lymphatic system in SLN, switches to pseudo SLN [15]. However, it is different from the NAC group, in which their NPV tended to be low by $74 \%$ with nine false-negative cases with the same factors, nine patients were with tumor size more than $4 \mathrm{~cm}(100 \%)$, and eight patients (88\%) were with Grade-III tumor. Therefore, the surgeon must be careful in performing SLNB with MBD to patients with Grade-3 tumors and tumor size more than $3 \mathrm{~cm}$.

In this study, SLN could not be found in 15 patients in the non-NAC group. The average age of the unidentified SLN group was 50 years, and this older condition could be one of the factors that caused identification failure in the final results. Increased fat tissue in the breast among older patients can decrease lymphatic flow and failure to identify SLN [14]. Higher tumor grade is known to be a negative factor for SLN identification in univariate analysis [14]. In this study, there were approximately $81 \%$ of Grade- 3 tumor cases found in the non-NAC group. This characteristic is following the study by Widodo et al. [13], showing that $54.8 \%$ of breast cancer patients in Indonesia had a Grade-III, 32.1\% Grade-II, and 13.1\% Grade-I tumors. However, in this study, there was no statistically significant relationship between age $(p=0.973)$, tumor grade $(p=0.275)$, and SLN identification. Meanwhile, in the NAC group, the identification of SLN on 44 patients was failed. The use of NAC can cause lymph node atrophy, which is microscopically proven by the study of Fan [10], in which there were lymphocyte loss, fibrosis, and histiocyte collection in lymphocytes.

This study has some limitations. The researchers only included clinically negative patients, but they did not perform an axillary biopsy if the axillary ultrasonography found a suspicious lymph node. Ultrasound-guided axillary lymph node biopsy will select patients with true negative axillary lymph nodes before surgery. We did not perform the clinical and pathological response evaluation in the NAC group with positive and negative metastases

\section{Conclusion}

This study proves that the NAC effect on SLNB technique with single methylene blue $1 \%$ can reduce the identification and false-negative rates of SLNB in breast cancer patients at low-resource country. Thus, the use of single methylene blue $1 \%$ injection in combination 
with NAC cannot be completely reliable as a diagnostic tool for lymph node mapping.

\section{References}

1. Gradishar WJ, Anderson BO, Abraham J, Aft R, Agnese D, Allison KH, et al. Breast cancer, Version 3.2020, NCCN clinical practice guidelines in oncology. J Natl Compr Canc Netw. 2020;18(4):452-78

PMid:32259783

2. Papathemelis T, Jablonski E, Scharl A, Hauzenberger $T$, Gerken M, Klinkhammer-Schalke M, et al. Sentinel lymph node biopsy in breast cancer patients by means of indocyanine green using the karl storz VITOM ${ }^{\circledR}$ fluorescence camera. Biomed Res Int. 2018;2018:6251468. https://doi.org/10.1155/2018/6251468 PMid:29780827

3. Ramírez-Nava G, Santos-Cuevas C, Ferro-Flores G, OcampoGarcía B, Chairez I, Gómez-Argumosa E, et al. Hybrid (2D/3D) dosimetry of radiolabeled gold nanoparticles for sentinel lymph node detection in patients with breast cancer. Contrast Media Mol Imaging. 2020;2020:2728134. https://doi. org/10.1155/2020/2728134

PMid:32489332

4. Lee SA, Lee HM, Lee HW, Yang BS, Park JT, Ahn SG, et al. Risk factors for a false-negative result of sentinel node biopsy in patients with clinically node-negative breast cancer. Cancer Res Treat. 2018;50(3):625-33. https://doi.org/10.4143/crt.2017.089 PMid:28759990

5. Faisal M, Sayed MG, Antonious K, Bakr AA, Farag SH. Prevention of lymphedema via axillary reverse mapping for arm lymph-node preservation following breast cancer surgery: A randomized controlled trial. Patient Saf Surg. 2019;13:35. https://doi.org/10.1186/s13037-019-0217-1 PMid:31807140

6. Lucci A, McCall LM, Beitsch PD, Whitworth PW, Reintgen DS, Blumencranz PW, et al. Surgical complications associated with sentinel lymph node dissection (SLND) plus axillary lymph node dissection compared with SLND alone in the American college of surgeons oncology group trial Z0011. J Clin Oncol. 2007;25(24):3657-63. https://doi.org/10.1200/jco.2006.07.4062 PMid:17485711

7. Langer I, Guller U, Berclaz G, Koechli OR, Schaer G, Fehr MK, et al. Morbidity of sentinel lymph node biopsy (SLN) alone versus SLN and completion axillary lymph node dissection after breast cancer surgery: A prospective Swiss multicenter study on 659 patients. Ann Surg. 2007;245(3):452-61. https://doi. org/10.1097/01.sla.0000245472.47748.ec PMid: 17435553

8. Rubio IT. Sentinel lymph node biopsy after neoadjuvant treatment in breast cancer: Work in progress. Eur J Surg Oncol. 2016;42(3):326-32. https://doi.org/10.1016/j.ejso.2015.11.018

\section{PMid:26774943}

9. Mamounas EP, Anderson SJ, Dignam JJ, Bear HD, Julian TB, Geyer CE, et al. Predictors of locoregional recurrence after neoadjuvant chemotherapy: Results from combined analysis of national surgical adjuvant breast and bowel project B-18 and B-27. J Clin Oncol. 2012;30(32):3960-6. https://doi.org/10.1200/ jco.2011.40.8369

PMid:23032615

10. Fan F. Evaluation and reporting of breast cancer after neoadjuvant chemotherapy. Open Pathol J. 2009;3(2):58-63.

11. Cohen LF, Breslin TM, Kuerer HM. Identification and evaluation of axillary sentinel lymph nodes in patients with breast carcinoma treated with neoadjuvant chemotherapy. Am J Surg Pathol. 2000;24(9):1266-72. https://doi. org/10.1097/00000478-200009000-00010 PMId: 10976701

12. Zurrida S, Veronesi U. Milestones in breast cancer treatment Breast J. 2015;21(1):3-12. https://doi.org/10.1111/tbj.12361 PMid:25494903

13. Widodo I, Dwianingsih EK, Triningsih E, Utoro T, Soeripto S. Clinicopathological features of Indonesian breast cancers with different molecular subtypes. Asian Pac J Cancer Prev. 2014;15(15):6109-13. https://doi.org/10.7314/ apjcp.2014.15.15.6109

PMid:25124582

14. Brahma B, Putri RI, Karsono R, Andinata B, Gautama W, Sari L, Haryono SJ. The predictive value of methylene blue dye as a single technique in breast cancer sentinel node biopsy: A study from Dharmais cancer hospital. World J Surg Oncol. 2017;15(1):41. https://doi.org/10.1186/s12957-017-1113-8 PMid:31205300

15. Borgstein PJ, Meijer S, Pijpers RJ, van Diest PJ. Functional lymphatic anatomy for sentinel node biopsy in breast cancer: Echoes from the past and the periareolar blue method. Ann Surg. 2000;232(1):81-9. https://doi. org/10.1097/00000658-200007000-00012

PMid:10862199

16. Shimazu K, Tamaki Y, Taguchi T, Takamura Y, Noguchi S. Comparison between periareolar and peritumoral injection of radiotracer for sentinel lymph node biopsy in patients with breast cancer. Surgery. 2002;131(3):277-86. https://doi.org/10.1067/ msy.2002.121378

PMid:11894032

17. Giuliano AE, Hunt KK, Ballman KV, Beitsch PD, Whitworth PW, Blumencranz PW, et al. Axillary dissection vs no axillary dissection in women with invasive breast cancer and sentinel node metastasis: A randomized clinical trial. JAMA. 2011;305(6):569-75. https://doi.org/10.1001/jama.2011.90 PMid:21304082

18. Soebhi T, Yarso KY, Sobri FB, Budhi IB. Methylene blue absorption in sentinel lymph node biopsy for early breast cancer after neoadjuvant chemotherapy. Asian Pac J Cancer Prev. 2020;21(6):1767-71. https://doi.org/10.31557/ apjcp.2020.21.6.1767

PMid:32592376 